This paper is published in the open archive of Mid Sweden University

DIVA http://miun.diva-portal.org

with permission of the publisher

Citation for the peer-reviewed published paper:

Torgnysdotter A, Wågberg L. Study of the joint strength between regenerated cellulose fibres and its influence on the sheet strength. ; Nordic Pulp \& Paper Research Journal. 2003;18(4):455-459.

URL to article at publishers site:

http://dx.doi.org/10.3183/NPPRJ-2003-18-04-p455-459 


\title{
Study of the joint strength between regenerated cellulose fibres and its influence on the sheet strength
}

\author{
Annsofie Torgnysdotter and Lars Wågberg, Mid Sweden University,Sundsvall, Sweden
}

KEYWORDS: Bonds, Bonding strength, Bonded area, Fibre bonding, Chemical bonding, Electrostatic charge, joints, dry strength, strain, swelling

SUMMARY: The joint strength between single fibres was investigated directly by measurements of perpendicular cross bonded fibres and compared with the corresponding paper properties. Regenerated cellulose fibres, rayon, were used. They were carboxymethylated in order to introduce charges to the fibres. Two different treatments were used to prepare fibres with charges located on the surface of the fibres and charges located throughout the bulk of the fibres. The charge characteristics, with respect to total charge and surface charge of the fibre were determined. The swelling caused by these charges was analysed with respect to pore volume distribution (NMR measurements) and water retention capacity (WRV). Charge characterisation showed that surface charged fibres could be produced by predrying fibres prior to carboxymethylation. Furthermore, WRV and NMR-relaxation measurements showed that an increase in the surface charge had no significant influence on the swelling whereas an increase in bulk charges had a large effect. The strength of the joints and the paper tensile properties are most affected by the surface charges, probably due to an increase in the molecular contact area with increasing charge. The results indicated that increased surface softness increased the critical strain of paper made from these modified fibres.

ADDRESSES TO THE AUTHORS: Annsofie Torgnysdotter, Mid Sweden University, FSCN, 85170 Sundsvall, Sweden, email: Annsofie.Torgnysdotter@mh.se Lars Wågberg, KTH, Dept. Fibre and Polymer Technology, div. Fibre Technology, Dkv 53, 10044 Stockholm, Sweden, c-mail:

Wagberg@pmt.kth.se

The main constituents of the paper dry strength are the joint strength between the fibres and the strength of the individual fibres. Together with the paper formation, these entities will determine the final strength of the paper. Network models to describe the properties of the paper have been presented by several authors (Rigdahl et al1986; de Ruvo 1986), and network theories for the description of paper strength have recently been published (Heyden et al 2001). In these latter theories, the strength of joints between fibres and the strength of fibres are included as separate parameters. However, since fibres are small, few exact measurements have been made of either fibre strength or joint strength between the fibres. There has, over the years, been a considerable debate as to which of these two components is the most important for paper strength (see for example Davison 1972).

Fibre strength is determined both by morphology and the strength of the interaction between the different chemical components in the fibre wall. Earlier work has addressed this. For example, the influence on the fibre strength by the orientation of the cellulose microfibrills was described several decades ago (Broughton, Wang 1955; Page et.al., 1972). During fibre processing, both the chemical composition of the fibre wall and the properties of the constituents in the fibre wall are changed and hence the properties of the fibres as raw material for papermaking will change (Wågberg, Annergren 1997). On a fibre level, fibre damage also affects the fibre strength. Page (1985) demonstrated that "curl, crimps, kinks and microcompressions" on the fibres significantly reduced the ability to fully utilise the fibre properties in the paper.

The second and perhaps even more important component in the development of paper dry strength is the development of the fibre/fibre joint strength. The word "joint" is used in this work instead of "bond" in order to suggest adhesion between the fibres to be the primary factor affecting paper strength rather than chemical bonding between the fibres. The description of the joints between fibres is not unique to paper but generally valid for adhesive contact between materials in general (Caulfield 1973; Kinloch 1980). To develop strong joints between fibres, several different factors have to be taken into account. The fibres need to come into close proximity with each other, brought about by the capillary forces during pressing and drying. Van der Waals forces and electrostatic forces also affect the interaction between the fibres in the fibre/water/fibre contact zone (Wågberg, Annergren 1997). The properties of the molecular contact zone depend on the softness of the fibre surface. Increased swelling is an indication of a decrease in the transverse elastic modulus of the surface (Scallan, Tigerström 1992; Lindstrom 1986). This in turn leads to a larger molecular contact zone (Emerton 1957; Paavilainen 1993). Paper strength has also been shown to be highly dependent of the outermost layers of the fibre (Barzyk 1997; Laine et al 1996). This may be probed by using for example Atomic Force Microscopy (AFM) as described by Nilsson et al. (2001).

When the fibres are in molecular contact the joint starts to develop and this is followed by a decrease of the specific surface area of the paper. This has been interpreted in terms of both inter- and intra-fibre bonding. The interaction most commonly suggested in the literature to explain the development of paper strength is probably hydrogen bonding. Results supporting this theory have been obtained by drying cellophane films together in close contact (Clark 1933) and the cohesion developed in a dried sheet can, according to McKenzie (1955), largely be attributed to hydrogen bonding between hydroxyl groups of carbohydrate chains. Considering the rough surfaces of wood fibres, the distance of 2-3 $\AA$ needed to 
form a hydrogen bond has led to a debate regarding the validity of the hydrogen bond theory. New data on the surface softness of the fibres (Scallan, Tigerstrom 1992; Nilsson et al 2001) however show the fibre surface to be a highly swollen gel where the macromolecules have high mobility. With highly mobile molecules in the outer layer of the surface, the molecules (amorphous hemicellulose or added polymers for example) may be able to interdiffuse and create strong joints between the fibres (McKenzie 1984). The interaction between these molecules may be of a hydrogen bond type. Pelton and co-workers (Pelton et.al. 2000) have presented results supporting McKenzie's theory, but the focus in this investigation was more on polymer compatibility than on hydrogen bonding. By studying the compatibility of adsorbed polymers during sheet consolidation, they found that polymer compatibilities at the fibre surface was important for the development of paper strength (Pelton et.al. 2000).

The strength of single fibre joints has been measured in only few studies. The joint strength is usually evaluated by application of the Page equation (Page 1969), where papers from the same type of fibres are pressed to different densities and a so-called relative bonded area (RBA) is estimated by measuring the light scattering of these papers. Utilising the Page equation and the relative bonded area, the tensile strength of the paper and data concerning fibre geometry, a "specific bond strength or a shear bond strength between the fibres can be calculated. Another more direct way of evaluating the joint strength between the fibres would be to measure directly the interaction between fibres in a sheet. Davison (1972) assessed the joint strength between fibres by pulling single fibres out from a paper and Stratton (1990) used a more direct approach and measured the joint strength directly in a perpendicular cross of two single fibres.

In order to clarify the importance of fibre interactions and molecular contact area on joint and paper strength in the present work, rayon fibres of different cross sectional area were chemically modified and the method of using single fibre crosses as described by Stratton (1990) was selected to determine the joint strength between fibres. To decrease the natural variations that occur in native fibres, regenerated cellulose fibres were used in this first investigation. As these regenerated fibres are rigid they neither have fibre wall nor fibrils at the surface. This will simplify the interpretation of detected effects of fibre modification. It must be stated that these massive fibres with a rather circular cross section will not behave exactly like natural fibres as they will not collapse into flat ribbons during drying. However, the joint strength between the regenerated fibres used in the present work will be an supplement to the measured adhesion behaviour of cellulose surfaces (Gunnars et al 2002; Rundlof et al 2000) to joint strength and paper strength of chemically modified native fibres (work currently underway in the laboratory of the authors).

\section{Materials and methods}

The fibres used in the experiments were rayon tow bright fibres from Svenska Rayon diameters of about 30 and 60 pm (5 and 20 dtex) cut by Bernhardt Stefferdt AB (Gothenburg, Sweden) to lengths of 4-mm. The fibres were thoroughly washed before use, first refluxed for 1 hour in deionised water at $10 \%$ pulp concentration then extracted in ethanol at $10 \%$ pulp concentration for 1 hour. Thereafter the fibres were reslushed in deionised water and dewatered. The washing continued until the first and last washing water had the same amount of total organic chloride (SS 028199 on a Shimadzu 5050A) and until Soxhlet extraction of the fibres at $10 \mathrm{~g}$ per litre in ethanol for 6 hours, showed a remaining amount of ethanolextractable compounds being less than $0.01 \mathrm{mg} / \mathrm{g}$.

To obtain two different charge distributions of the fibres, bulk-charged and surface-charged fibres, a modified carboxymethylation was used (Fors 2000). To achieve bulk-charged fibres, the washed pulp was solvent exchanged to ethanol (spectrophotometric grade) prior to the carboxymethylation. The solvent exchange from water to ethanol was carried out in six steps with a fourhour equilibrium time for each step. To achieve a surfacecarboxymethylated pulp the fibres were hornified (dried from water at $105^{\circ} \mathrm{C}$ ) before carboxymethylation. The carboxymethylation was then performed according to Walecka (1956). The surface-carboxymethylated fibres were dried in the sodium form at $50 \%$ R.H wheares the bulk-carboxymethylated fibres were not dried at all prior to use.

Fibre dimensions such as length, width and shape factor (projected fibre length divided with the true fibre length) were determined in the Fibremaster Analysis equipment. To check whether the crystallinity of the cellulose was changed by the carboxymethylation, both untreated and carboxymethylated fibres were investigated with CP/MAS ${ }^{13} \mathrm{C}-\mathrm{NMR}$ (at $292 \pm 1 \mathrm{~K}$ ) on a Bruker AMX-300 instrument operating at 7.05 T ( Hult 2001).

It is known that the charge of cellulosic fibres is essential for their physical properties and hence also for their papermaking properties. The total charge of the fibres was determined by conductometric titration (Katz et. al. 1984) and the surface charge by polyelectrolyte adsorption (Wågberg et al. 1985; Winter et. al. 1986). In this method a high molecular polydimethyldiallylammonium chloride (polyDADMAC) with a molecular mass of $1.2 * 10 " \mathrm{~g} /$ mole was used. The adsorption was carried out at $\mathrm{pH} 8$.

To obtain a description of the fibre swelling the water retention capacity (Scallan, Carles 1972) and the pore structure of the fibres were analysed. To determine the pore structure the fibres were subjected to NMR relaxation measurements on a Bruker Avance spectrometer $\left(5.87 \mathrm{~T}\right.$ magnet, ${ }^{2} \mathrm{H}$ resonance frequency $38.4 \mathrm{MHz}$ ) (Andreasson, Wågberg 2001). According to (Li et al, 1993) this method provides a good description of the pore size distribution of the pores within the fibre wall.

Handsheets were prepared in the Rapid-Kothen Blattbildner (ISO 5269-2). The thickness of the sheets was measured according to standard SS 843009 . Forcedisplacement curves of the sheets were measured according to SCAN-P 67:93.

The fibre crosses were prepared according to the method initially described by Stratton and Colsson (1990) 
except that the fibres were not dyed. After preparation, the fibre crosses were stored at room temperature until they were tested. An Environmental Scanning Electron Microscope (ESEM 2020) from Electro Scan, USA was used to study the behavior of rayon fibers and the joints between the fibres during loading. A tensile testing stage was designed at the Swedish Pulp and Paper Research Institute (STFI) by modifying the Electroscan standard tensile stage, see Fig. 1. During tension, both stage jaws moved outwards simultaneously while the test piece remained centered below the detector to permit imaging. A water-cooled unit was attached to the stage in order to maintain a stable test piece temperature and to remove the local heat caused by the electron beam in long-term experiments. The load cell from Sensotec $\mathrm{h}$ a d a working range of $0-150$ gms.

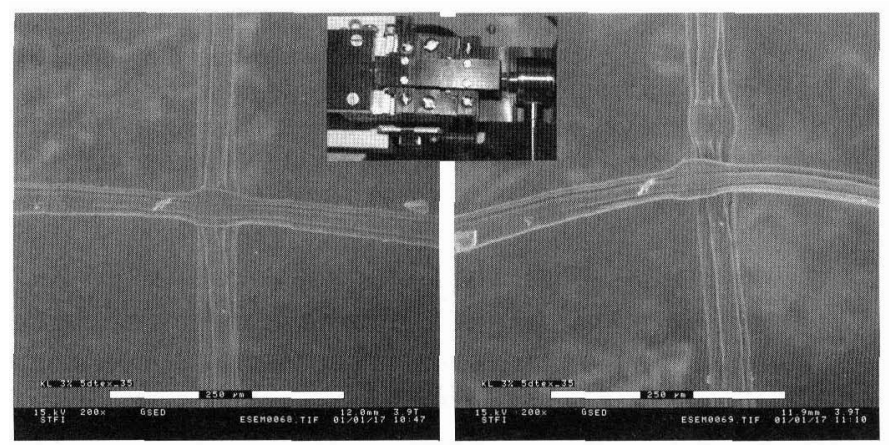

Fig. I _Rayon fibres joined together in a fibre cross. Joints strengths analyzed in tensile stage.

The sample was glued to the table of the load bench with Loctite 401" glue. The glue was allowed to dry for five minutes before the bench was placed in the ESEM. The conditions inside the microscope were $27^{\circ} \mathrm{C}$ and 4 torr, approximately $20 \% \mathrm{RH}$. The sample was conditioned for 15 minutes before measurement. The microscope was operating at $15 \mathrm{kV}$ accelerating voltage with a $1 \mathrm{~mm}$ working distance of the stage, the displacement rate was $1 \mu \mathrm{m} / \mathrm{s}$.

\section{Results and discussion}

The influence of the carboxymethylation reaction on the cellulose crystallinity was examined using CP/MAS ${ }^{1:} \mathrm{C}$ NMR. There was no difference in the spectra between a treated and an untreated fibre, which indicates that the cellulose was not affected on the supermolecular level by the carboxymethylation reaction and was mainly of the cellulose Il crystalline form.

According to the STFI fibremaster measurements the weighted fibre length was 4.00-4.08 $\mathrm{mm}$ for both the 5 dtex and 20 dtex. The fibrewidths were $36.3-36.6 \mathrm{pm}$ for the 5dtex fibres and 65-67.8 $\mu \mathrm{m}$ for the 20dtex fibres, and the aspect ratio of the fibre cross section was 92.6$96.8 \%$ for both the 5 dtex and the 20 dtex fibres respectively. These values were not affected by the carboxymethylation reactions.

Charge and charge distribution of the fibres are important properties for both joint and paper properties since they affect the swelling of the fibre surface and hence the transverse elastic modulus of the surface. This in turn will affect the molecular contact area and may also affect the molecular mobility at the surface. A large difference in total charge was found for fibres that had been hornified and ethanol-exchanged before carboxymethylation. The hornified fibres reached a plateau at $100 \mu \mathrm{eq} . / \mathrm{g}$ whereas the solvent-exchanged fibres reached a level of $550 \mu \mathrm{eq} . / \mathrm{g}$, see Fig. $2 a$. Fig. $2 b$ on the other hand shows that the amount of adsorbed high molecular polyDADMAC reaches the same level for the two types of fibres, despite the five times higher total charge of the solvent-exchanged fibre. These results indicate that the surface of these fibres becomes saturated with charges at a level of about $100 \mu \mathrm{eq} / \mathrm{g}$.


Fig. $2 a$ and $h$. Effect of carboxymethylatibn on hornified and solvent-exchanged fibres measured as (a) total charge and (b) polyelectrolyte adsorption.

The total amount of charges normally has a large influence on the swelling or water-holding capacity (WRV) of fibres (Grignon, Scallan, A.M., 1980; Lindstrom, Carlsson 1978) as well as the pore size distribution inside the fibre wall (Li 1993). As shown in Fig. 3, bulk-charged fibres gave a significantly higher WRV and a higher average pore size and a wider pore volume distribution compared to the surface charged fibres. This is most likely due to the internal swelling of the bulk-charged fibre. As indicated in Fig. 3, the hornified fibres did not show any significant swelling since there was no change in WRV or in pore volume distribution. This most probably depends on the location of the charges on the surface of the fibres, only creating a softer surface of the fibres in water. 

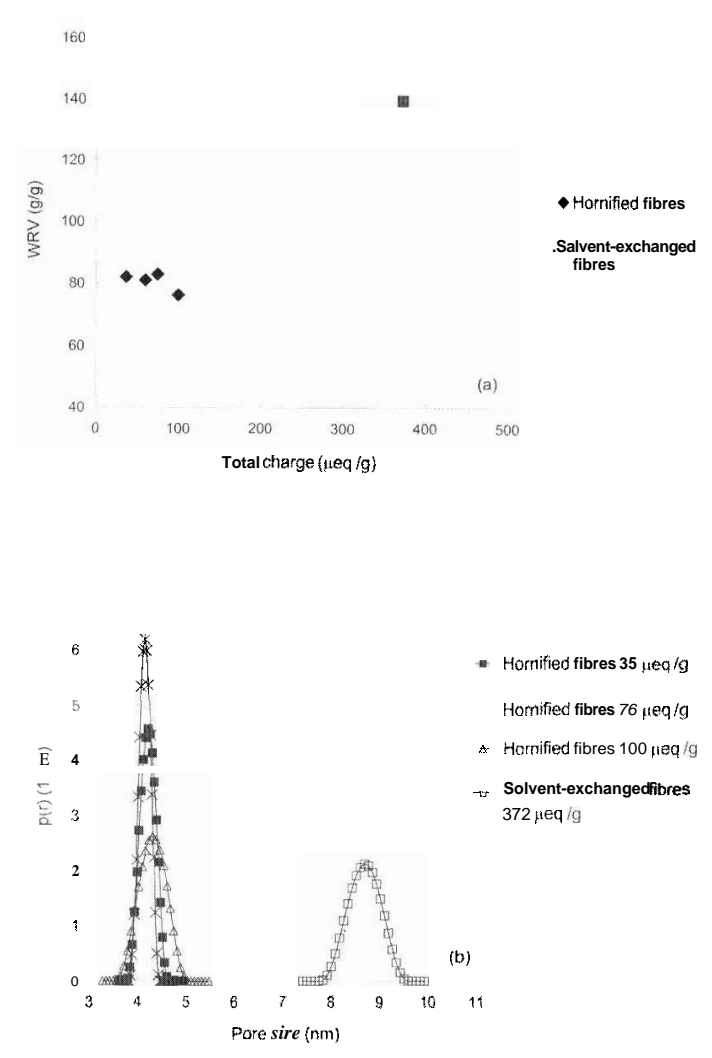

Fig. $3 a$ and $h$. Fibre swelling measured as (a) water retention capacity (WRV) and (b) pore volume distribution NMR measurements.

As discussed in the introduction, the joint strength between fibres is determined by several factors, such as molecular contact area and mixing of materials in the external parts of the adjacent fibres etc. The final network strength is naturally also dependent on fibre strength, fibre orientation and chemical interactions to mention only a few factors.

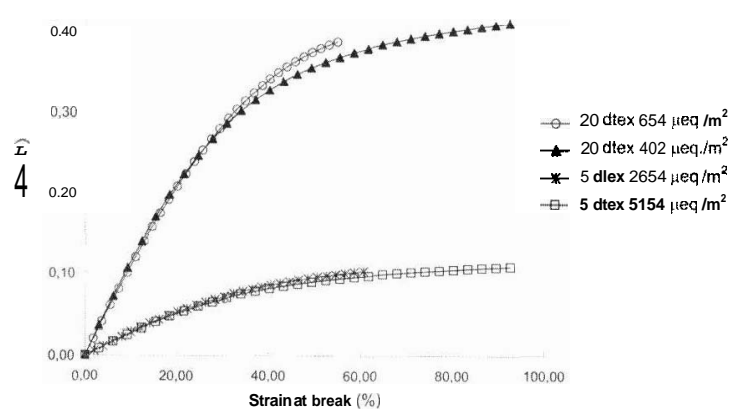

Fig.4. Strength- strain curves of carboxymethylated rayon fibres. The total charge as showed in the figure legend has been normalised with respect to the macroscopic surface area assuming that the fibres are smooth cylinders.

The fibre strength was tested as the carboxymethylation might have changed the properties of the fibres. Fig. 4 shows that the carboxymethylation had no effect on the stress at failure but reduced the strain to failure. However, since the strain is greater than that usually found for sheets, it is assumed that the change in strain at break of the fibres will not affect the strain properties of the sheets made from these fibres.

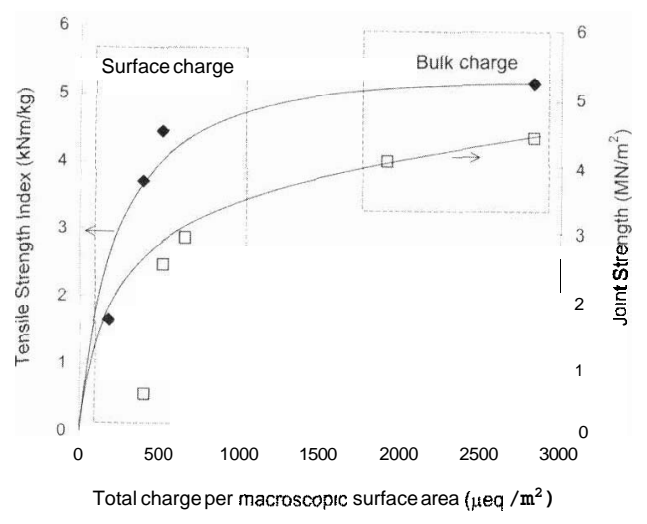

Fig.5. Measurements of fibre cross joint strength and tensile strength index of paper. The variation coefficient of the tensile strength index is $5-10 \%$. The variation coefficient of the joint strengths is around $20 \%$. Approximately 25 fibre crosses were measured in each point. The total charge as showed in the figure legend has been normalised with respect to the macroscopic surface area assuming that the fibres are smooth cylinders.

In order to establish whether or not there is a link between fibre properties, joint strength and paper strength, both single fibre crosses and paper sheets were prepared from the same kind of fibres. The results for fibre crosses and paper sheets are shown in Fig. 5. The total charge of the fibres has been recalculated into total charge per square meter, and used as a basis for comparison of fibres with different dimensions. Dimensions of the fibres and the mass per 10000 meters of the fibres were

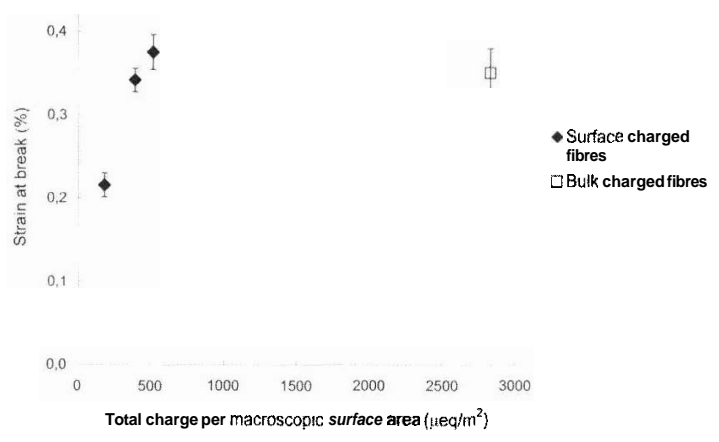

Fig.6. Strain at break of paper made from surface-charged fibres and bulk-charged fibres, the variation coefficient of the measurements are $5-7 \%$.

used for this calculation where the fibres were assumed to have a cylindrical shape. As clearly shown in Fig. 5 the same trend in strength can be found for both the joints and the paper. In turn this shows that surface charges are by far most important for the development of joint and paper strength than the bulk charges. These results are in accordance with earlier measurements of papers with differences in charge distribution of the fibres (Barzyk 1997; Laine 1996).

As shown in Fig. 6, the strain at break of the paper 
increases with the charge of the fibres. This indicates that the critical strain of each individual joint did increase since the critical strain of the single fibres was reduced. At the present time we have no direct explanation of this phenomenon. It may be speculated that the higher charge and higher surface softness may permit a greater mixing of the external surface layers of adjacent fibres creating a large contact zone in the z-direction of the fibres. During loading of the paper this in turn means that a larger part of the fibre surface will be affected by the stress in the fibre/fibre joint resulting in a larger overall strain of the paper. This hypothesis is being tested in current investigations.

It should also be added that the chemical treatment of the surface did not affect the density of the sheet and that this straightforward comparison therefore can be made between the sheets.

\section{Conclusion}

The joint strengths of single fibre crosses of regenerated cellulose fibres were measured in order to link the properties of the joints formed during web consolidation to the strength properties of the paper. It was found that surface charges of fibres are most important for the development of both joint strength and paper strength. It is suggested that this may be due to surface softening of the fibres, increasing the molecular contact area and promoting a better molecular mixing of the external material on adjacent fibres. Such a mixing of polymers on the fibre surface also seems to increase the critical strain of the network.

\section{Acknowledgement}

Bo Andreasson is thanked for assistance in the pore volume distribution measurements and Tomas Larsson STFI for solid state NMR measurements. The authors acknowledge Dr. Shannon Notley for linguistic revision. Kent Malmgren, SCA Research, is appreciated for fruitful discussions. FSCN(Fibre Science Communication Network) is thanked for financial support. Finally, Carin Bergstrom at SCA Graphic Research is thanked for skilful experimental assistance with the initial preparation of fibre crosses.

\section{Literature}

Andreasson B, WIgberg L. 2002; Pore structure of pulp fibres with different yields and its influence on paper strength. Accepted for publication in Celluose

Barzyk, D., Page, D. H., Ragauskas, A., J. Pulp and Paper Sci., 23, J59, (1997).

Broughton, G., Wang, J. P., Tappi, 38, 412(1955).

Caulfield, D.F, Tappi, 56, 102-106, (1973).

Clark, J. d'A., Pap. Trade J., 97, 25 (1933).

Davison, R.W., Tappi, 55, 567-573, (1972).

de Ruvo, A., Fellers, C. And Kolseth, P.;"Descriptive theories for the tensile strength of paper", in "Paper- Structure and Properties", J.A. Bristow and P. Kolseth (Eds.), Marcel Dekker Inc.,1986 ISBN 0-8247-7560-0, pp.267-279.

Emerton, H.W.,Fundamentals of the beating process, British Paper Board ind. Res. Ass.,(1957).

Fors, C., Licentiate thesis, Royal Institute of Technology, Stockholm (2000).
Grignon ,J. and Scallan, A.M., J. Appl. Polymer Sci., 25, 829 (1980).

Gunnars, S. and WIgberg, L., Paper submitted to Cellulose, (2002).

Heyden, S. and Gustafsson, P-J.,"Stress-strain performance of paper and fluff by network modelling", in "The science of papermaking", Trans. 12th Fundamental Res. Symp. In Oxford, C.F. Baker (Ed.), The Pulp Paper Fundamental Res. Soc., 2001,ISBN 0 954112601 , pp.1385.

Hult, E. L., Larsson P. T., Iverssen, T., Nordic Pulp Paper Res. J 16, 33, (2001).

Katz, S., Beatson, R. P., and Scallan, A. M., Svensk Papperstidn. 87, R48 (1984).

Kinloch, A.J., J. Material Sci, 15, 2141-2166, (1980).

Laine, J. (1996) "The effect of surface chemical composition and charge on the fibre and paper properties of unbleached and bleached kraft pulps" Doctoral thesis, Helsinki University of Technology.

Lindstrom, T., Carlsson, G., "The effect of chemical enviroment on fibre swelling", EUCEPA symposium, Warsawa, 32, (1978).

Lindstrom, T.: In "Paper- Structure and Performance", A. Bristow and P. Kolseth, Eds., Marcel Dekker, Inc. New York, Basel, 1986 , pp. 75 and pp. 99 .

Li T-Q, Henriksson U, Ödberg L., Nordic Pulp Paper Res. J. 8, $326-330$, (1993).

McKenzie, A.W., Aust. J. Appl. Sci., 6, 208-, (1955).

McKenzie, A.W., Appita, 37, 580-, (1984).

Nilsson, B., Wbgberg, L. and Gray, D.;"Conformability of wet pulp fibres at short length scales", in "The science of papermaking", Trans, 12th Fundamental Res. Symp. In Oxford, C.F. Baker (Ed.), The Pulp Paper Fundamental Res. Soc., 2001,ISBN 0 $954112601,2001 . p p .211$

Paavalainen, L., Pap.Puu, 75, 689, (1993).

Page, D.H., Tappi, 52, 674 (1969).

Page, D. H., El-Hosseiny, F, Winkler, K., Bain, R., Pulp Pap. Mag. Can., 73, 72 (1972).

Page, D.H., Seth, R.S. and EI Hosseiny, F.: "Strength and Chemical Composition of Wood Pulp Fibres", Transactions of the Eight Fundamental Research Symposium held at Oxford, September 1985, p.77.

Pelton, R., Zhang, J., WIgberg, L. and Runlof, M.; Nordic Pulp Paper Res. J., 15, 2000.

Rapid Kothen Blattbildner (delivered by PTE AB) standard procedure ISO 5269-2.

Rigdahl, M. and Hollmark, H.;"Network mechanics", in "PaperStructure and Properties", J.A. Bristow and P. Kolseth (Eds.), Marcel Dekker Inc., 1986 ISBN 0-8247-7560-0, pp.241-266.

Rundlof, M., Karlsson, M., WIgberg, L., Poptoshev, E., Rutland, M. and Claesson, P. J. Colloid Interface Sci., 230, 441447 (2000).

Scallan, A.M. and Carles, J.E.; J. Svensk Papperstidn. 75, 699 (1972)

Scallan, A.M. and Tigerstrom, A.; J. Pulp Paper Sci. 18, J188 (1992).

Stratton, R. A., Colson, N. L., Mat. Res. Soc. Symp. Proc., 197, 173-181, (1990).

Walecka, J. A., Tappi 39, 458, (1956).

Winter, L., WIgberg, L., Ödberg, L., Lindstrom, T., J. Colloid Interface Sci., 2, 537-543, (1986).

WIgberg, L., Winter, L. and Lindstom, T.: Papermaking raw materials, Transactions of the eight fundamental research symposium held at Oxford, Mechanical Eng. Publ. Ltd., London (1985) 917.

Wågberg,L: and Annergren, G.;"Physico-chemical characterisation of papermaking fibres", In "Fundamentals of Papermaking Materials", C.F. Baker (Ed.), Transactions of the I Ith Fundamental Research Symposium held at Cambridge, Pira International. 1997. Leatherhead UK, ISBN 185802209 6,pp.I-82

Manuscript received January 29,2003 Accepted May, 2003 